\title{
Entropy characterisation of overstressed capacitors for lifetime prediction
}

\author{
Angel Cuadras*, Ramon Romero, Victoria J. Ovejas \\ Grup d'Instrumentació, Sensors i Interficies, Departament d'Enginyeria Electrònica, Escola d'Enginyeria de Telecomunicació i Aeronàutica de Castelldefels EETAC, Universitat \\ Politècnica de Catalunya, Barcelona Tech (UPC), Castelldefels, Barcelona, Spain
}

\section{A R T I C L E IN F O}

Article history:

Received 29 April 2016

Received in revised form 19 October

2016

Accepted 22 October 2016

Available online $\mathrm{xxx}$

Keywords:

Entropy

Capacitor

Joule effect

Reliability

Damage

Wear out

ESR

Ageing

\section{Introduction}

Capacitors are energy storage components ubiquitous in electronic and electrical engineering applications. Several types of capacitors are available: ceramic, film, aluminium electrolytic, laminated ceramic, tantalum electrolytic, supercapacitors or flow supercapacitors. Electrolytic and supercapacitors have the largest capacities. They are manufactured in many foundries worldwide, and some of the largest producers are Panasonic, Vishay, Kemet, and Murata.

In this contribution, we are interested in capacitor ageing and failure characterisation. Capacitors are exposed to wear or damage while in use, which jeopardizes circuit performance. Degradation can be caused by different mechanisms. Typical failure modes and their causes are shown in Table 1 .

In the scientific literature, there are many models regarding capacitor ageing and reliability, from different approaches: physicochemical, which characterises dielectric material properties [2,3]; statistical, which evaluates failure distributions [4-6]; electrical [7], with a special focus on equivalent series resistance (ESR) evolution [8,9] or impedance spectroscopy [10,11] and thermal [12-15]. From the thermal viewpoint, reversible entropy in supercapacitors has been considered in similar terms as in batteries [16,17]. In this case, reversible heat is related to ion movement in the electrolyte $[12,14]$. Moreover, the industry has also produced a large literature of information about ageing. International standards specify how ageing tests must be conducted [18-20], i.e., capacitors are biased at their nominal DC voltage

\footnotetext{
* Corresponding author.

Email address: angel.cuadras@upc.edu (A. Cuadras)
}

with or without a superimposed AC signal. From these tests, empirical data to predict the capacitor lifetime is obtained. Panasonic provides the expected life $L$ ratio for its parts as a function of temperature [1] by the following equation:

$$
L=L_{0} 2^{\frac{T_{0}-T}{10}}
$$

where $T$ and $T_{0}$ are the capacitor temperature and the maximum guaranteed capacitor temperature respectively, and $L_{0}$ is the guaranteed life of the capacitor. Moreover, the typical random failure rate, $\lambda$ can be determined. It relates the expected capacitor life ( $L$ in hour) to its operating performance [21] by the following equation:

$$
\lambda=\frac{4 \cdot 10^{6} N V_{a}^{3} C^{\frac{1}{2}} 2^{\frac{\left(T_{\mathrm{a}}-T_{\mathrm{m}}\right)}{10}}}{L_{0} V_{r}^{2}}
$$

$N$ is the number of the studied capacitors, $V_{\mathrm{a}}$ is the applied voltage, $C$ the capacitance of a single capacitor, $T_{\mathrm{a}}$ and $T_{\mathrm{m}}$ are the actual and the maximum permitted core temperatures respectively, $L_{\mathrm{b}}$ is the base life in hours at $T_{\mathrm{m}}$ and $V_{\mathrm{r}}$ is the rated voltage. The expressions given by (1) and (2) are typically empirical and provided by the manufacturers.

We suggest that the available models and relationships are either not directly dependent on intrinsic capacitor parameters (such as capacitance, ESR, EPR, dielectric permittivity or loss tangent) or they are statistical fits. However, in both cases they suggest the critical ef- 
Table 1

Failure modes and mechanisms of Aluminum electrolytic capacitors (simplified from Ref. [1]).

\begin{tabular}{|c|c|c|}
\hline Causes & Failure mechanisms & Effects \\
\hline $\begin{array}{l}\text { - Overvoltage im- } \\
\text { pressed } \\
\text { - Excessive ripple } \\
\text { - Reverse voltage ap- } \\
\text { plied } \\
\text { - Severe charging/dis- } \\
\text { charging } \\
\text { - AC voltage applied } \\
\text { - Used at high temper- } \\
\text { atures } \\
\text { - Used for a long pe- } \\
\text { riod }\end{array}$ & $\begin{array}{l}\text { - Increase in internal tempera- } \\
\text { ture } \\
\text { - Increase in internal pressure } \\
\text { - Reduction in anode foil ca- } \\
\text { pacitance } \\
\text { - Reduction in cathode foil ca- } \\
\text { pacitance } \\
\text { - Deterioration of oxide film } \\
\text { - Electrolyte dry-up } \\
\text { - Insulation breakdown } \\
\text { - Corrosion }\end{array}$ & $\begin{array}{l}\text { - Air tightness failure } \\
\text { of sealing } \\
\text { - Capacitance reduces } \\
\text { - Losses increases } \\
\text { - Leakage current in- } \\
\text { crease } \\
\text { - Short circuit } \\
\text { - Open circuit }\end{array}$ \\
\hline
\end{tabular}

fect of temperature on operating performance. An ageing description that considers the physical parameters of the capacitor beyond a statistical approach and that is able to predict the lifetime and internal capacitor degradation, could be very useful. This type of description is true not only for capacitors but also for other energy storage systems, e.g. batteries or fuel cells.

Thus, looking at Table 1 we observe that the capacitors either evolve to open or short circuit conditions depending on the degradation mechanism. However, in both cases the capacitor ages, so an ageing model must simultaneously consider both the increase and decrease of internal parameters, such as current, voltage, capacitance or ESR for a positive ageing. We can infer that ageing and the internal parameters must be related, at least, through a quadratic relation. Dissipated power is the first quadratic option, but it is not a function of state. Conversion from power dissipation to ageing degradation can be achieved through entropy generation. Because ESR depends on temperature and ageing and dissipates power when biased, we consider that entropy can become a bridge between these parameters. We previously characterised the irreversible entropy generation rate $\sigma_{\mathrm{s}}$ for resistors [22], which here we extend to capacitors. Moreover, entropy has already been applied to damage characterisation [23-26] and was suggested as a valuable parameter for instrumentation and measurement [27]. Thus, we aim at finding a simple method to predict their ageing evolution to foresee their lifetimes. We investigate entropy evolution to characterise commercial capacitor damage and to find the relationship between failure mechanisms and time-to-failure $(L$ in $(1))$. The final aim is to explain capacitor degradation in terms of positive irreversible entropy generation. Thus, a threshold for maximum allowable damage will be established.

\section{Theoretical approach}

We took a thermodynamic approach to capacitor failure, using the first and second laws of thermodynamics [28]

$$
\begin{aligned}
& d U=d W+d Q+d E_{\mathrm{irr}} \\
& \dot{S}=\dot{S}_{\mathrm{e}}+\dot{S}_{\mathrm{i}}
\end{aligned}
$$

with
$\dot{S}_{\mathrm{i}} \geq 0$

in a non-equilibrium system considering the approximation of local equilibrium. The dot over the variable represents a time derivative, i.e., $\dot{S}=d S / d t$. In (3), $U, W, Q$, and $E_{\text {irr }}$ are the internal, stored, heat and irreversible damage energies, respectively. In (4), subindices $e$ and $i$ refer to external (entropy exchange) and internal entropy (entropy generation), respectively [29]; thus, entropy remains a valuable state function. We are interested in $\dot{S}_{\text {i }}$, includes thermal dissipation and ageing, and must be positive. The stored energy ( $\mathrm{dW}$ ) for a capacitor is well-known and described by the following:

$$
W=\frac{1}{2} C V^{2}
$$

Heat is dissipated at the series resistance due to the Joule effect:

$$
Q=R_{\mathrm{s}} \cdot I^{2}
$$

No literature about $E_{\text {irr }}$ was found; thus, its form is unknown at present. In terms of the entropy generation rate $\dot{S}=d S / d t$, for electrical systems, it is commonly written as [28]:

$$
\dot{S}=\frac{P}{T}=\frac{I V}{T}
$$

where $P$ is the total input electrical power, and $I$ and $V$ are the current and voltage drop between the external terminals, respectively. The power dissipated in the capacitor was invested by the Joule effect and capacitor degradation. In terms of irreversible entropy, (stored energy is reversible and thus, we do not consider it in ageing), the heat entropy generation (Joule effect) is written as follows:

$$
\dot{S}=\frac{R_{\mathrm{s}} I^{2}}{T}
$$

where $R_{\mathrm{S}}$ is the ESR, $I$ the electrical current, and $T$ is the capacitor temperature.

\section{Materials and methods}

Commercial electrolytic capacitors were investigated (listed in Table 2). These capacitors are made of aluminium foils with boric acid acting as electrolyte creating an $\mathrm{Al}_{2} \mathrm{O}_{3}$ dielectric, as illustrated in Fig. 1. Their tolerance is $\pm 20 \%$ at $120 \mathrm{~Hz}$ and $20{ }^{\circ} \mathrm{C}$, operating temperature ranges from $-40{ }^{\circ} \mathrm{C}$ to $85^{\circ} \mathrm{C}$ and an endurance of $1000 \mathrm{~h}$ at $85^{\circ} \mathrm{C}$, according to the manufacturer's data. From an electric viewpoint $[1,21]$, a real capacitor is typically modelled using an ideal ca-

Table 2

List of investigated capacitors in this contribution. All parts are Panasonic, with a tolerance of $\pm 20 \%$ and an expected lifetime of $1000 \mathrm{~h}$ tested at $85^{\circ} \mathrm{C}$ except for ECA0JHG101, which has been tested at $105^{\circ} \mathrm{C}$.

\begin{tabular}{lll}
\hline Model & Capacity & $V_{\max }$ \\
\hline ECEA0GKS330 & $33 \mu \mathrm{F}$ & $4 \mathrm{~V}$ \\
ECEA0JKS330 & $33 \mu \mathrm{F}$ & $6.3 \mathrm{~V}$ \\
ECEA0GKA101 & $100 \mu \mathrm{F}$ & $4 \mathrm{~V}$ \\
ECA0JHG101 & $100 \mu \mathrm{F}$ & $6.3 \mathrm{~V}$ \\
\hline
\end{tabular}




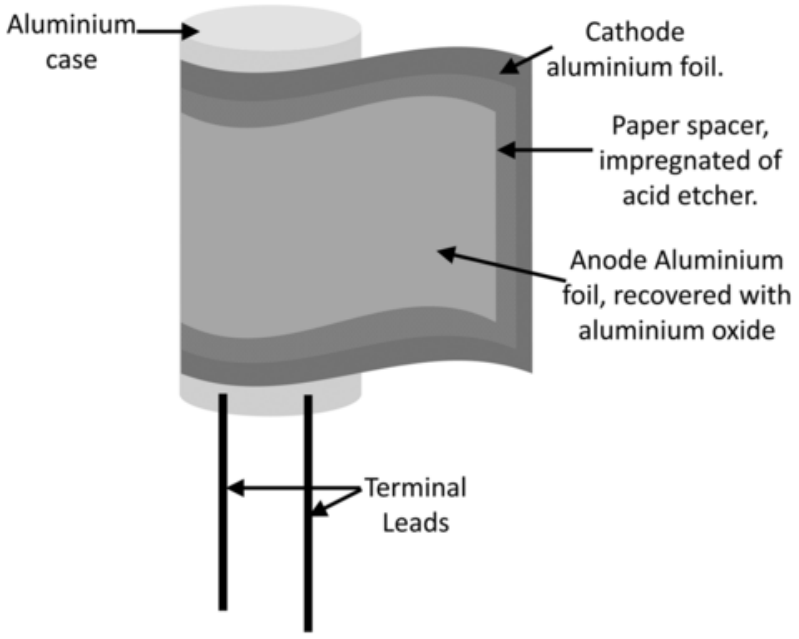

Fig. 1. Schematic of an electrolytic capacitor.

pacitance, an ESR, $R_{\mathrm{s}}$, and an equivalent parallel resistance (EPR), $R_{\mathrm{p}}$. The ESR accounts for the terminal and contact resistances, electrolyte resistance and dielectric losses in the dielectric oxide layer. The EPR accounts for the leakage current through the capacitor. ESR decreases both with temperature and frequency and depends on ageing $[1,21]$.

Capacitors were biased at room temperature in order to measure their power dissipation as shown in the setup illustrated in Fig. 2. They were connected in series with a control resistor of $10 \Omega$ and $25 \mathrm{~W}$ to measure the input current. Applied bias to the R-C system ranged from $20 \mathrm{~V}$ to $40 \mathrm{~V}$, using a Promax FAC662B voltage source, which is well above the maximum rated voltage. Both continuous and pulsed biases were considered. In continuous bias, the capacitor was connected to the source through a control resistor. The voltage drop at the control resistor allowed us to determine the current. A pulsed bias was achieved by commuting the switch with the relay $\mathrm{K} 1$ at a duty cycle of $14.5 \%(0.5 \mathrm{~s} / 3 \mathrm{~s}$ ON/OFF $)$. When $\mathrm{K} 1$ was $\mathrm{ON}$, the capacitor was charging. When K1 was OFF, the capacitor first discharged through K2. Subsequently, K2 switched off and K3 switched on to connect the capacitor to the $5 \mathrm{~Hz}$ AC source (Vin in Fig. 2). Capaci- tance was determined from the amplitude change in the low pass filter $C-R_{\mathrm{FPB}}$ according to the following:

$$
\frac{V_{\mathrm{o}}}{V_{\mathrm{in}}}=\frac{1}{\sqrt{1+\left(\omega R_{\mathrm{FPB}} C\right)^{2}}}
$$

$$
\varphi=\operatorname{arctg}\left(-\omega R_{F P B} C\right)
$$

All the experiments were conducted at room temperature. The temperature was monitored using a PT1000 sensor that was mechanically attached to the top of the aluminium capsule capacitor and thermally connected with a heat sink compound (Dow Corning 340). Current, voltage and temperature were acquired using a microcontroller data acquisition system. The data was transferred to a computer and processed to infer the entropy generation rate and entropy accumulation. Switches and relays were controlled from the microcontroller. From the data, the knowledge of the capacitor deterioration can be obtained instantaneously.

\section{Results}

We summarise the results obtained from the electrically stressed capacitors under various experimental conditions, in order to determine the relationship between resistor damage and entropy generation. Time evolution of current, voltage and temperature was monitored among many capacitors and situations. The delivered power to the capacitor was estimated as the product of its voltage drop and current through the relation: $P=V \cdot I$. Entropy rate, $\dot{S}$, was then obtained from (8). The effects of voltage overstress on the capacitors are illustrated in Fig. 3. We have classified the capacitors in three categories: $\mathrm{N}$ as new or biased at low power, they do not show external changes; B when external changes are visible and $\mathrm{E}$ when the capacitor has exploded due to gasification. In Table 3, the evolution of the $33 \mu \mathrm{F}$ series is presented. Similar behaviours are found in the other capacitors. At lower voltages, the damage is less significant than at larger voltages. However, depending on rated voltages, capacitors can

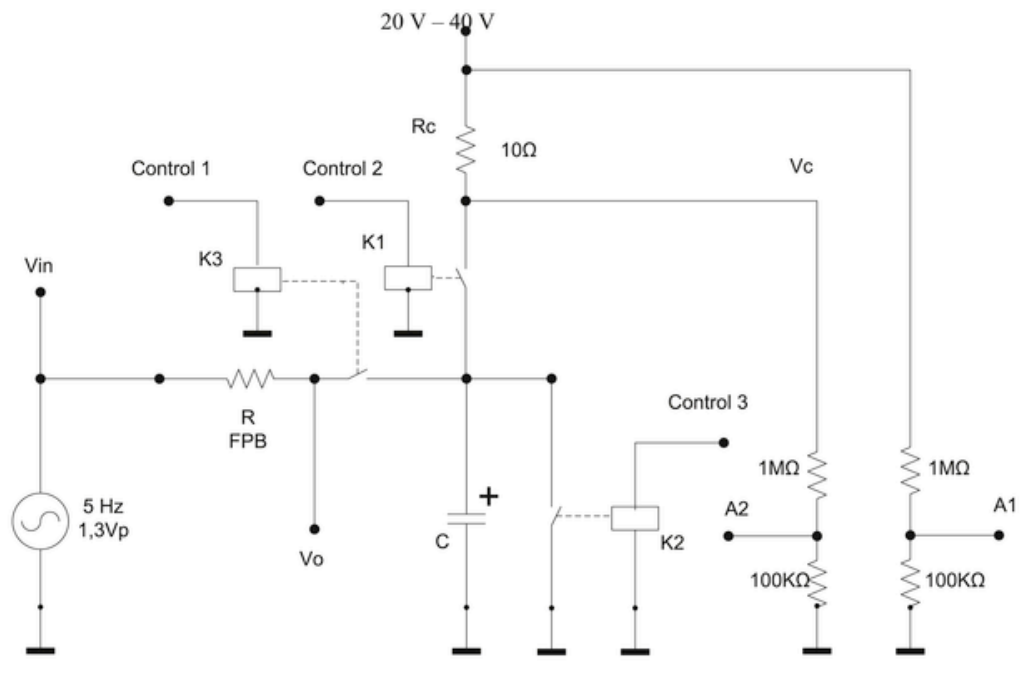

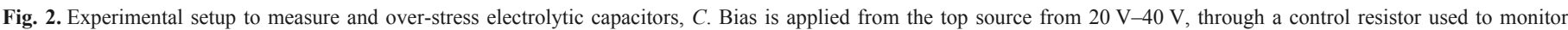

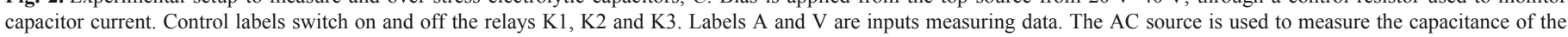
capacitor in real time during the pulsed measurements. The serial resistor R_FPB is $330 \Omega$ and $1 \mathrm{k} \Omega$ for the $100 \mu \mathrm{F}$ and $33 \mu \mathrm{F}$ [30]. 


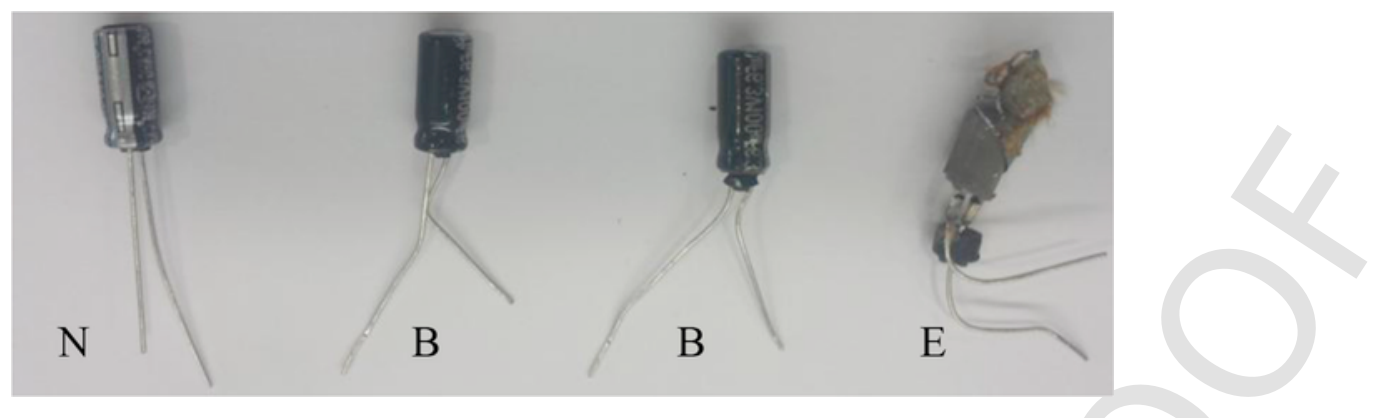

Fig. 3. Capacitors after being overcharged. We have classified them as follows: not affected (N), burned-out (B) and exploded (E) [30].

Table 3

Capacitor state at the end of the experiment. (N: no change, B: burned-out, E: exploded).

\begin{tabular}{|c|c|c|c|c|c|}
\hline & $20 \mathrm{~V}$ & $25 \mathrm{~V}$ & $30 \mathrm{~V}$ & $35 \mathrm{~V}$ & $40 \mathrm{~V}$ \\
\hline $33 \mu \mathrm{F} 6.3 \mathrm{~V}$ pulsed & $\mathrm{N}$ & $\mathrm{N}$ & $\mathrm{B}$ & $\mathrm{E}$ & $\mathrm{B}$ \\
\hline $33 \mu \mathrm{F} 6.3 \mathrm{~V} \mathrm{CC}$ & $\mathrm{N}$ & $\mathrm{B}$ & $\mathrm{B}$ & $\mathrm{B}$ & $\mathrm{B}$ \\
\hline $33 \mu \mathrm{F} 4 \mathrm{~V}$ pulsed & $\mathrm{N}$ & $\mathrm{B}$ & $\mathrm{E}$ & $\mathrm{E}$ & $\mathrm{B}$ \\
\hline $33 \mu \mathrm{F} 4 \mathrm{~V} \mathrm{CC}$ & $\mathrm{B}$ & $\mathrm{B}$ & $\mathrm{E}$ & $\mathrm{E}$ & $\mathrm{E}$ \\
\hline
\end{tabular}

explode even at low powers. Next, we will connect the behaviour in Table 3 with the $\dot{S}$ evolution.

The time evolution of current, voltage, power, temperature, entropy rate and capacitance for a selected capacitor are illustrated in Fig. 4. The key experimental parameters are instantaneous dissipated power $P$ and temperature $T$. From these to magnitudes we can infer the entropy generation rate $\dot{S}$ using (8). Clearly, there is a dependence between degradation and $\dot{S}$. When the input power is small $(20 \mathrm{~V})$, the entropy generation rate is small. When the input power increases, $\dot{S}$ increases first, which indicates that the capacitor is dissipating power. Then, at a certain time, $\dot{S}$ evolves to zero, which means that the capacitor gets an open because the applied voltage is kept at the input voltage until the end of the experiment. This threshold time can be used to indicate time-to-failure of the capacitor. As long as the input voltage increases, the threshold time decreases and maximum $\dot{S}$ increases. This is not true for $40 \mathrm{~V}$, which fails later than the lower biased voltages. This is in agreement with Table 3 . A $40 \mathrm{~V}$ biased capacitor did not explode, as was the case with those biased at $30 \mathrm{~V}$ and $35 \mathrm{~V}$. This is a valuable result, because $\dot{S}$ has an implicit fingerprint of the failure mechanism. For the sake of comparison, online capacitance evolution is also depicted in Fig. 4. We observe a monotonous decrease in capacitance that increases with injected power. The initial magnitude of the capacitance is larger than nominal, because it is measured at a low frequency. The nominal capacitance $33 \mu \mathrm{F}$ is measured at $120 \mathrm{~Hz}$. Below this frequency, the capacitance increases up to $44 \mu \mathrm{F}$ at $0.01 \mathrm{~Hz}$.

A dependence on the entropy rate was also found as a function of capacitance (Fig. 5a) and maximum allowed voltage (Fig. 5b). Both behaviours are expected. On the one hand, for the same rated voltage, a larger capacitance yields a larger failure time. Conversely, for the same capacitance, a larger rated voltage increases the time-to-failure. Thus, the entropy generation rate is sensitive to both capacitance and rated voltage.

\section{Discussion}

The experimental results demonstrated that $\dot{S}$ is a promising indicator for monitoring capacitor ageing. Some issues remain to be discussed from the previous results. The first issue is to compare this method with other conventional methods for capacitor ageing; we consider impedance spectroscopy (IS). The second issue is to consider the effect of measuring surface temperature instead of core temperature, which would be more appropriate. Finally, we evaluate the energy and entropy balance inside the capacitor according to thermodynamic laws.

\subsection{Impedance spectroscopy of capacitors}

New and aged capacitors were studied by impedance spectroscopy using a Biologic VSP with a frequency response analyser, from $10 \mathrm{mHz}$ to $200 \mathrm{kHz}$. New capacitors fit well with a $R_{\mathrm{s}}-C$ model, as shown in Fig. 6. The $R_{\mathrm{s}}$ (ESR) was around $2.6 \Omega$. No contribution below $1 \mathrm{M} \Omega$ was found for EPR. This result is in agreement with ageing tests, where no power leakage was found (when power evolves to zero it indicates a degradation towards open circuit).

Aged capacitors were studied after they were removed from the ageing setup and cooled. When the capacitors were overstressed, first $R_{\mathrm{s}}$ increased, as expected, and later the capacitance value was also modified. The increase in $R_{\mathrm{s}}$ was associated with electrolyte dry-up, according to Table 1 . IS results are consistent with $\dot{S}$ but have the disadvantage of being monitored offline and with special (and usually expensive) equipment.

\subsection{Temperature measurement and the entropy profile}

The temperature measured at the surface was delayed with respect to the power dissipated at the capacitor core. This was due to heat propagation from the heat generation inside to the outside of the capacitor [31]. To evaluate this lag, we modelled the capacitor as a simple cylinder and estimated the core temperature using the heat transfer equations using the MATLAB finite element routine. We observed that the core temperature increases faster than the measured temperature, reaches a maximum (around $10 \mathrm{~K}-20 \mathrm{~K}$ above the measured temperature) and then converges to the surface temperature, in the stationary state. This effect slightly modifies the shape of the $\dot{S}(\mathrm{t})$ curves by decreasing the maximum observed $\dot{S}$. However, the time scale, and thus, the threshold was not modified. Therefore, the stated assumptions remain valid. Moreover, considering that entropy was measured in $\mathrm{K}$ means that the introduced error at the temperature peak was on the order of $20 \mathrm{~K} / 370 \mathrm{~K} \cdot 100=5 \%$. Core temperature measurements are necessary for a more accurate $\dot{S}$ quantification, but in this case the model would need to take into account the distribution of heat production inside the capacitor making the calculations more 


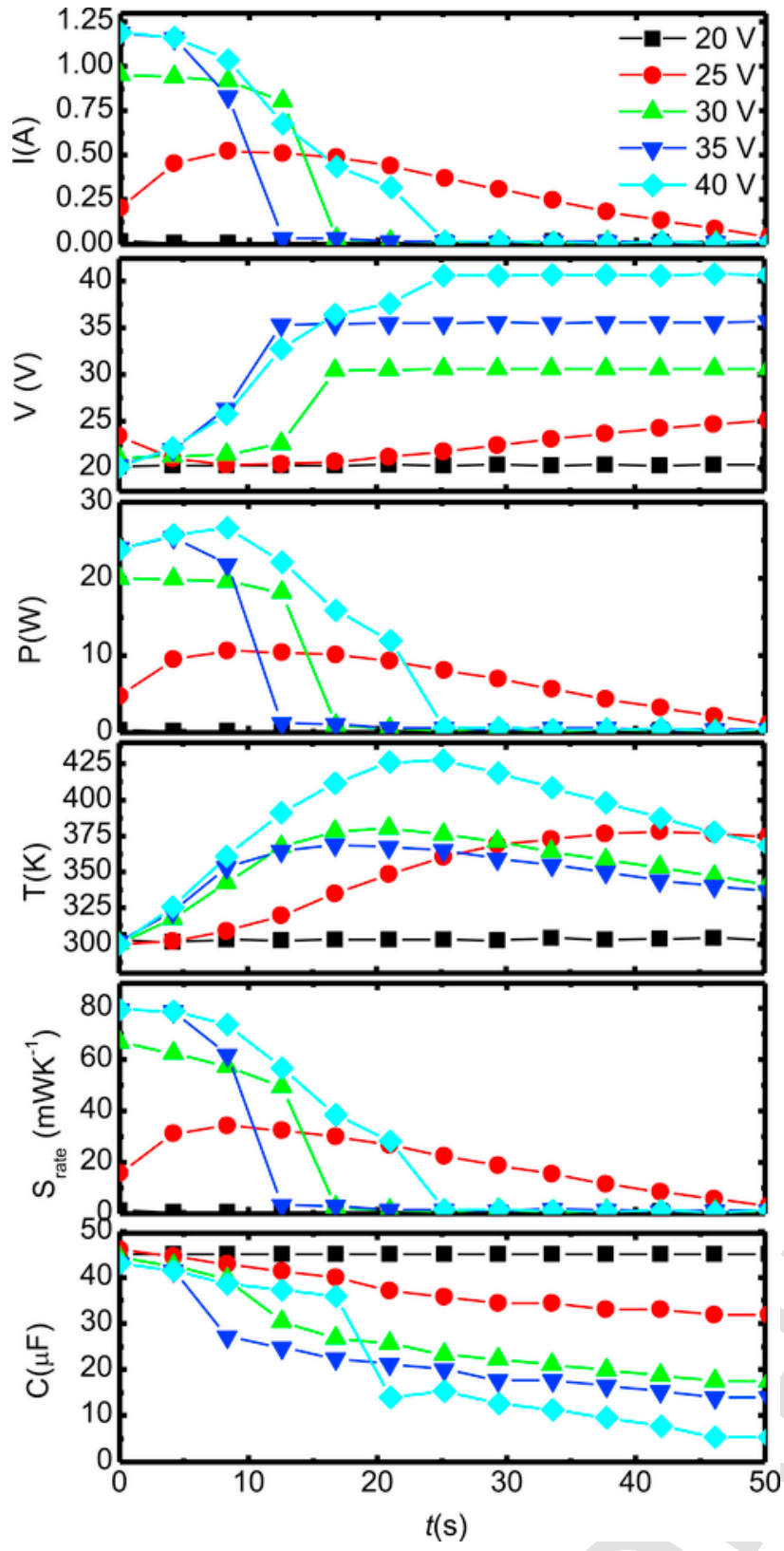

Fig. 4. Time evolution of current, capacitor voltage drop, power, temperature, entropy generation rate $\dot{S}$ and capacitance for the capacitor $33 \mu \mathrm{F}$ capacitor biased with a $4 \mathrm{~V}$ pulsed excitation. Dissipated power increases with the bias. A small entropy generation at $20 \mathrm{~V}$ is observed, in general as long as the voltage increases so does $\mathrm{S}$. The threshold can be used as a time to failure indicator Capacitance decreases with degrading, depending on the applied voltage.

complex. In its present form, the method remains very simple and is able to monitor capacitors time-to-failure when sudden changes in $\dot{S}$ are detected.

\subsection{The energy balance}

We now look for a reliable expression for entropy damage, related to $E_{\text {irr }}$ in (3). In a plot of $P(T)$ (see Fig. 7), we observed, first, more effects than previously found in single resistors [22]. The effects were divided into four different regions. We found a linear behaviour in the range of $300 \mathrm{~K}-320 \mathrm{~K}$, which is the regular operating temperature
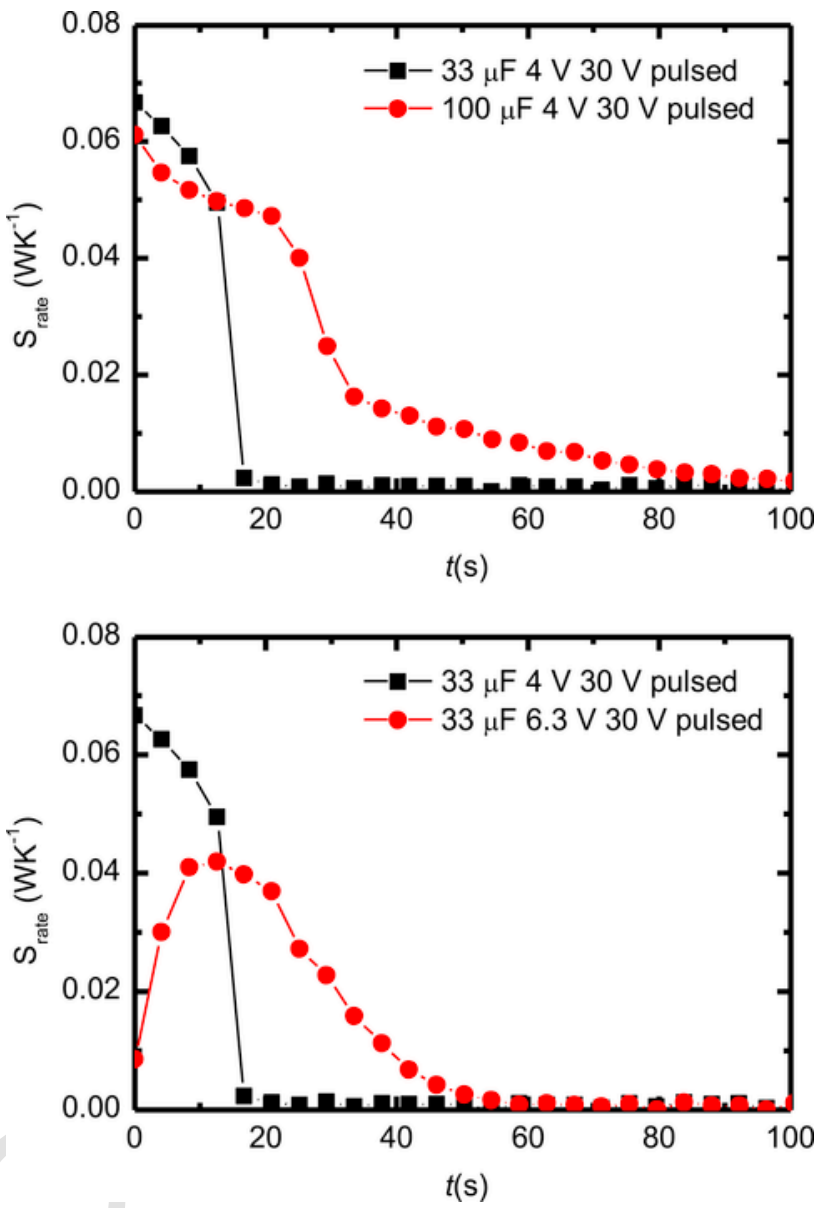

Fig. 5. Continuous excitation at $30 \mathrm{~V}$ a) Comparison between two capacitors of the same rated voltage and different capacitance. b) Comparison between same capacitance and different rated voltage.

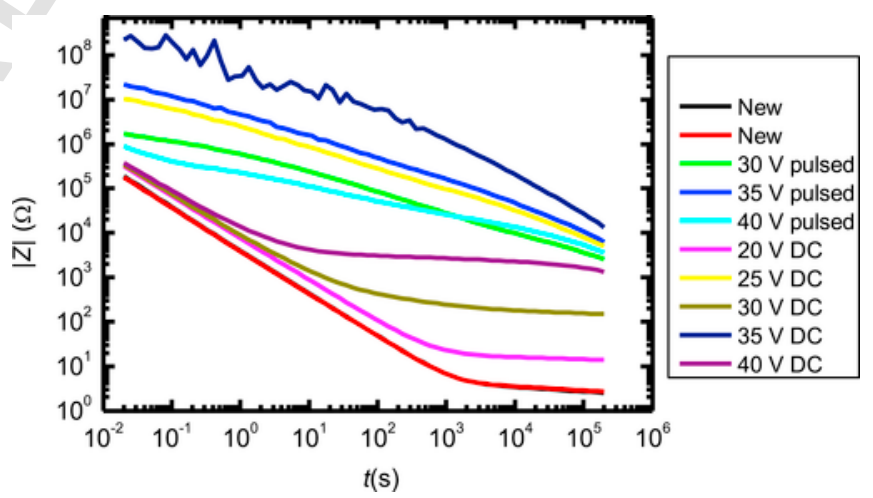

Fig. 6. Impedance spectroscopy of $33 \mu \mathrm{F} 4 \mathrm{~V}$ for pulsed and continuous (DC), in new and aged capacitors.

range for these capacitors. Then a strong increase up to $350 \mathrm{~K}\left(85^{\circ} \mathrm{C}\right)$. From $350 \mathrm{~K}$ to $380 \mathrm{~K}$, the power increases with temperature up to $380 \mathrm{~K}\left(105^{\circ} \mathrm{C}\right)$, which is the maximum operating temperature before gasification begins [1]. This plot agrees with the typical data provided by manufacturers: $85^{\circ} \mathrm{C}$ is the maximum temperature of these capacitors, and $105^{\circ} \mathrm{C}$ is the gasification temperature at which the capacitor may explode. This phase transition is more evident in the energy $E(T)$ plot (Fig. 7b), where the delivered energy is plotted 


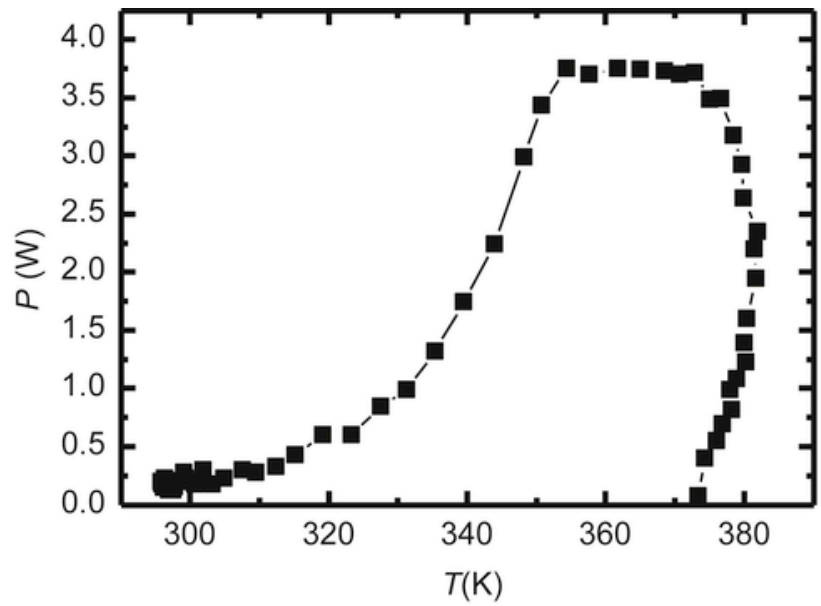

(a)

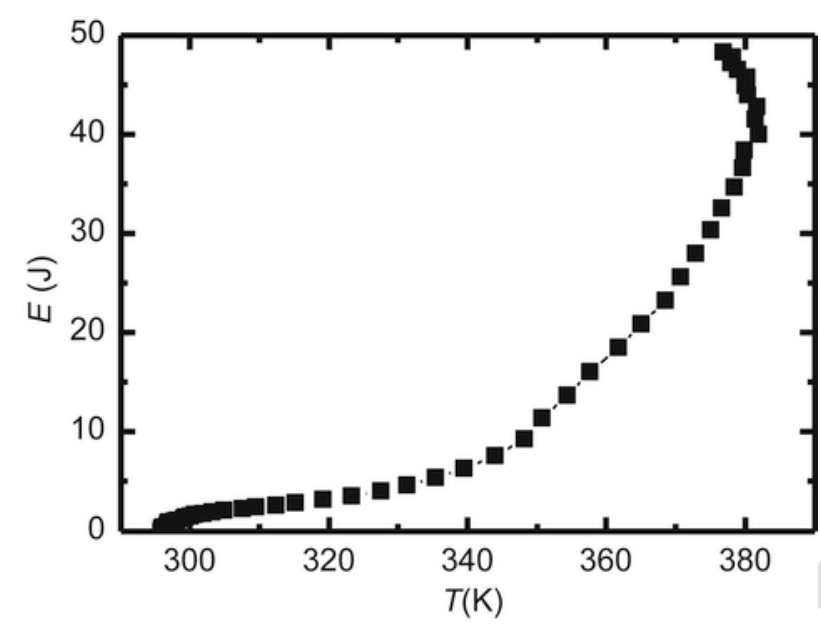

(b)

Fig. 7. (a) Power and (b) energy delivered to the capacitor as a function of temperature for $33 \mu \mathrm{F} 4 \mathrm{~V}$ at a $20 \mathrm{~V}$ pulse. We observed a maximum temperature around $380 \mathrm{~K}$, which is the maximum operating temperature for capacitors after which gasification occurs.

as a function of temperature. At $378 \mathrm{~K}\left(105^{\circ} \mathrm{C}\right)$, we found an increase of energy at constant temperature, which is a fingerprint of a phase transition, in particular, vaporisation of the electrolyte. Phase transitions necessarily imply a discontinuity in the entropy.

In the linear range, input power was dissipated as heat at the $R_{\mathrm{s}}$ and stored in the capacitor. Eventually, this power can partially damage the capacitor structure, considering a capacitor modelled in an $R-C$ circuit, where the capacitance stores energy and the resistance dissipates heat and ages [22].

We can refine our approach in the linear regime. Ageing should be studied mainly in the range from $290 \mathrm{~K}$ to $320 \mathrm{~K}$, where the linear behaviour occurs. Therefore, after recovering Eq. (1), we can rewrite it as

$$
\begin{aligned}
& \dot{S}=\dot{S}_{\mathrm{e}}+\dot{S}_{\mathrm{i}} \\
& \frac{V I}{T}=\frac{\dot{Q}_{\mathrm{e}}}{T}+\dot{S}_{\mathrm{i}} \\
& V I=\dot{Q}_{\mathrm{e}}+\dot{S}_{\mathrm{i}} T
\end{aligned}
$$

where $\dot{Q}_{\mathrm{e}}$ is the heat exchanged with the surroundings. The results are depicted in Fig. 8. A general trend can be found, as $E_{\text {irr }}$ increases with input voltage. However, to quantify this degradation between the studied samples, a better knowledge of core temperature was necessary, as stated in the previous section, because in this case the temperature error was large enough to overpass the ageing entropy resolution.

\section{Conclusions}

We proposed a method to estimate ageing in electrolyte capacitors based on a measurement of entropy generation rate, $\dot{S}$. We found that $\dot{S}$ depended on the applied voltage, and thus on the ageing mechanism. Moreover, $\dot{S}$ was sensitive to capacitance and geometrical capacitor design. A projection of time-to-failure and a simple model for damage $\dot{S}$ was proposed. Further measurements to quantitatively validate the model, specifically, those leading to an accurate determination of capacitor core temperature would be required. We believe that this approach could be easily extended to all types of capacitors, batteries and fuel cells.

\section{Acknowledgments}

We would like to thank Dr. Eduard Vives, from University of Barcelona for his fruitful discussions and Francis Lopez for the technical support. Victoria J. Ovejas also acknowledges the financial support of FPU contract given by MECD. This research has been partially supported by the project TEC-2015-63899-C3-1-R (MINECO/FEDER).

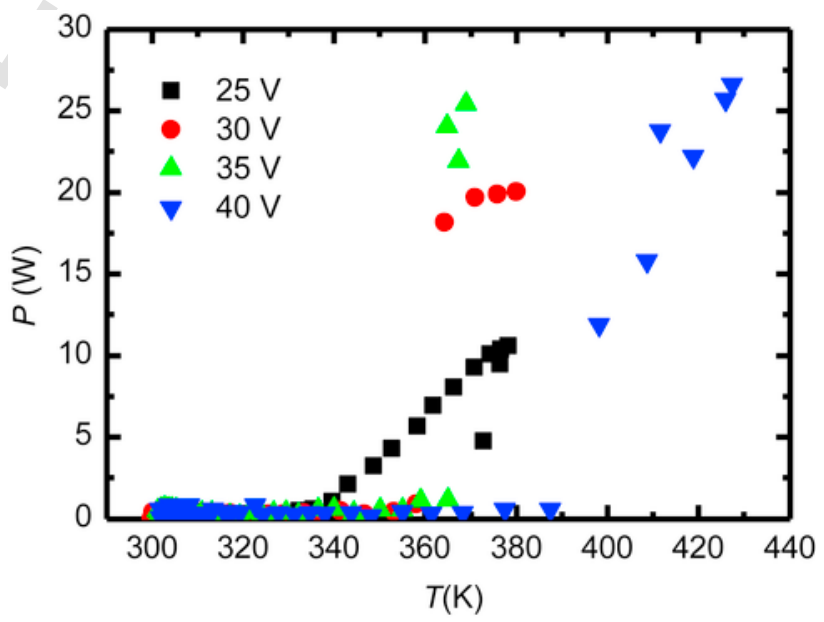

Fig. 8. Delivered power as a function of temperature for $33 \mu \mathrm{F} 4 \mathrm{~V}$ and pulsed bias. 


\section{References}

[1] Panasonic, aluminum electrolytic capacitors, Capacit. Bus. Div. (2002). https:// industrial.panasonic.com/content/data/CP/PDF/Alumi/AL_technical_guide_E. pdf. last accessed Oct. 2016

[2] J. Yamamatsu, N. Kawano, T. Arashi, A. Sato, Y. Nakano, T. Nomura, Reliability of multilayer ceramic capacitors with nickel electrodes, J. Power Sources 60 (1996) 199-203, http://dx.doi.org/10.1016/S0378-7753(96)80011-5.

[3] Y. Rao, C.P. Wong, Material characterization of a high-dielectric-constant polymer-ceramic composite for embedded capacitor for RF applications, J. Appl. Polym. Sci. 92 (2004) 2228-2231, http://dx.doi.org/10.1002/app.13690.

[4] H.S. Endicott, B.D. Hatch, R.G. Sohmer, Application of the Eyring Model to capacitor aging data, In: Annu. Rep. 1962 Conf. Electr. Insul. CEI 1962, vol. 12, 2016, pp. 47-50, http://dx.doi.org/10.1109/EIC.1962.7466672.

[5] P. Cygan, J.R. Laghari, Models for insulation aging under electrical and therma multistress, IEEE Trans. Electr. Insul. 25 (1990) 923-934, http://dx.doi.org/10. $1109 / 14.59867$.

[6] F. Perisse, P. Venet, G. Rojat, J.M. Rétif, Simple model of an electrolytic capacitor taking into account the temperature and aging time, Electr. Eng. 88 (2006) 89-95, http://dx.doi.org/10.1007/s00202-004-0265-z.

[7] W.J. Sarjeant, J. Zirnheld, F.W. MacDougall, Capacitors, IEEE Trans. Plasma Sci. 26 (1998) 1368-1392, http://dx.doi.org/10.1109/27.736020.

[8] K. Harada, A. Katsuki, M. Fujiwara, Use of ESR for deterioration diagnosis of electrolytic capacitor, IEEE Trans. Power Electron. 8 (1993) 355-361, http://dx doi.org/10.1109/63.261004.

[9] A. Lahyani, P. Venet, G. Grellet, P.J. Viverge, Failure prediction of electrolytic capacitors during operation of a switchmode power supply, IEEE Trans. Power Electron. 13 (1998) 1199-1207, http://dx.doi.org/10.1109/63.728347.

[10] E.H. El Brouji, O. Briat, J.M. Vinassa, N. Bertrand, E. Woirgard, Impact of calendar life and cycling ageing on supercapacitor performance, IEEE Trans. Veh. Technol. 58 (2009) 3917-3929, http://dx.doi.org/10.1109/TVT.2009.2028431.

[11] R. Kötz, P.W. Ruch, D. Cericola, Aging and failure mode of electrochemical double layer capacitors during accelerated constant load tests, J. Power Sources 195 (2010) 923-928, http://dx.doi.org/10.1016/j.jpowsour.2009.08.045.

[12] J. Schiffer, D. Linzen, D.U. Sauer, Heat generation in double layer capacitors, J. Power Sources 160 (2006) 765-772, http://dx.doi.org/10.1016/j.jpowsour.2005. 12.070 .

[13] O. Bohlen, J. Kowal, D.U. Sauer, Ageing behaviour of electrochemical double layer capacitors. Part I. Experimental study and ageing model, J. Power Sources 172 (2007) 468-475, http://dx.doi.org/10.1016/j.jpowsour.2007.07.021.
[14] O. Bohlen, J. Kowal, Dirk Uwe Sauer, Ageing behaviour of electrochemical double layer capacitors. Part II. Lifetime simulation model for dynamic applications, J. Power Sources 173 (2007) 626-632, http://dx.doi.org/10.1016/j. jpowsour.2007.07.059.

[15] A.L. D'Entremont, Thermal Modeling of Electrochemical Capacitors, University of California, Los Angeles, 2015. http://escholarship.org/uc/item/4r11b122.

[16] B. Fultz, Y. Reynier, J. Graetz, T. Swan-Wood, P. Rez, R. Yazami, Origin of the entropy of intercalation of $\mathrm{Li}$ into LixCoO2, in: D.B. Chandra, L. Schlapbach (Eds.), Adv. Mater. Energy Convers. II, 2004, pp. 311-316.

[17] Y. Reynier, J. Graetz, T. Swan-Wood, P. Rez, R. Yazami, B. Fultz, Entropy of $\mathrm{Li}$ intercalation in LixCoO2, Phys. Rev. B - Condens. Matter Mater. Phys. 70 (2004) 1-7, http://dx.doi.org/10.1103/PhysRevB.70.174304.

[18] IEC, IEC60143-1 Series Capacitors for Power Systems Part 1-General, 2004.

[19] VITA, VITA 51.2 Physics of Failure Reliability Predictions, 2011.

[20] IEC/EN 61709, Electric Components. Reliability. Reference Conditions for Failure Rates and Stress Models for Conversion, 2016.

[21] CornellDubilier, Aluminum Electrolyte Capacitor application guide, (n.d.). http: //www.cde.com/resources/catalogs/AEappGUIDE.pdf (last accessed: Oct. 2016).

[22] A. Cuadras, J. Crisóstomo, V.J. Ovejas, M. Quilez, Irreversible entropy model for damage diagnosis in resistors, J. Appl. Phys. 165103 (2015) http://dx.doi. org/10.1063/1.4934740.

[23] J. Lemaitre, J.-L. Chaboche, Mechanics of Solid Materials, Cambridge University Press, 1990.

[24] C. Basaran, C. Yan, Damage mechanics of solder joints, J. Electron. Packag. 120 (1998) 379-384

[25] M. Amiri, M.M. Khonsari, On the thermodynamics of friction and wear-A review, Entropy 12 (2010) 1021-1049, http://dx.doi.org/10.3390/e12051021.

[26] M. Naderi, M. Amiri, M.M. Khonsari, On the thermodynamic entropy of fatigue fracture, Proc. R. Soc. A Math. Phys. Eng. Sci. 466 (2010) 423-438, http://dx. doi.org/10.1098/rspa.2009.0348.

[27] M. Amiri, M. Modarres, An entropy-based damage characterization, Entropy 16 (2014) 6434-6463, http://dx.doi.org/10.3390/e16126434.

[28] G. Lebon, D. Jou, J. Casas-Vázquez, Understanding Non-equilibrium Thermodynamics: Foundations, Applications, Frontiers, Springer-Verlag, Germany, 2008http://dx.doi.org/10.1007/978-3-540-74252-4.

[29] D. Kondepudi, I. Prigogine, Modern Thermodynamics: from Heat Engines to Dissipative Structures, first ed., Wiley, West Sussex, England, 1998.

[30] R. Romero Sangüesa, Estudi de l'envelliment de sistemes electrònics, 2015. http://upcommons.upc.edu/handle/2117/77378 (last accessed Oct. 2016)

[31] S.G.J. Parler, Thermal modeling of aluminum electrolytic capacitors, In: Conf. Rec. 1999 IEEE Ind. Appl. Conf. Thirty-forth IAS Annu. Meet. (Cat. No.99CH36370), 1999, pp. 1-12, http://dx.doi.org/10.1109/IAS.1999.799180. 